DOI: $10.36910 / 6775-2524-0560-2019-36-1$

УДК 004.05(075.8)

Андрущак I.Є., Кошелюк В.А., Сіваковська О.М., Потейчук М.І. ${ }^{1)}$, Марценюк В.П. ${ }^{2)}$

Луцький національний технічний університет ${ }^{1)}$

Університет Бєльсько-Бяли, Польща ${ }^{2)}$

\title{
FEATURES OF INFORMATION TECHNOLOGY DISTRIBUTION OF RADIO WAVES BY FREQUENCY BANDS.
}

\begin{abstract}
Андрущак І.Є., Кошелюк В.А., Сіваковська О.М., Потейчук М.І., Марценюк В.П. Особливості інформаційної технології поширення радіохвиль за діпапазонами частот. В статті приведено обгрунтування поширення радіохвиль. Викладено основи їх поширення в неоднорідній атмосфері. Наведено принципи послаблення напруженості поля та класифікація основних моделей радіотрас, як відкритих, так і в разі наявності перешкод різного типу, в тому числі таких, які екранують поле. Приділяється увага сучасним моделям послаблення радіохвиль в умовах щільної забудови у мегаполісах, а також всередині будівель і приміщень.
\end{abstract}

Ключові слова: радіохвилі, локації, кросування, радіотраса.

Андрущак И.Е., Кошелюк В.А., Сиваковска Е.Н., Потейчук М.И., Марценюк В.П. Особенности информационной технологии распространения радиоволн за дипапазонамы частот. · В статье приведены обоснования распространения радиоволн. Изложены основы их распространение в неоднородной атмосфере. Приведены принципы ослабление напряженности поля и классификация основных моделей радиотрас, как открытых, так и в случае наличия препятствий различного типа, в том числе таких, которые экранируют поле. Уделяется внимание современным моделям ослабления радиоволн в условиях плотной застройки в мегаполисах, а также внутри зданий и помещений.

Ключевые слова: радиоволны, локации, кроссировки, радиотраса.

Andrushchak I.Ye., Koshelyuk V.A., Sivakovska O.M., Poteychuk M.I., Martsenyuk V.P. Features of information technology distribution of radio waves by frequency bands. The article justifies the propagation of radio waves. The basics of their distribution in an inhomogeneous atmosphere are outlined. The principles of field strength reduction and classification of the main radio path models, both open and in the case of interference of various types, including those that screen the field, are presented. Attention is paid to modern models of attenuation of radio waves in the conditions of dense construction in metropolitan areas, as well as indoors and buildings.

Keywords: radio waves, locations, cross-country, radio.

Formulation of the problem. The radio communication system is intended to transmit information over a distance by means of radio signals.

Information expressed in a specific form is a message to be transmitted over a distance. For the purpose of providing information, any language characterized by a set of signs and rules for their use is used. A set of characters containing some information is a message. The message can be continuous (analog) and discrete. To transmit information in the radio system, the message must be converted into a primary electrical signal. For example, sound pressure when transmitting voice messages will turn into a microphone into a voltage. The conversion of discrete primary electrical signals into combinations of elementary signals is called encoding. The primary electrical signal is, as a rule, low frequency and cannot be efficiently emitted in a radio propagation medium. Therefore, it must be converted to a high frequency signal called a radio signal.The conversion of the primary electrical signal into a radio signal is accomplished by changing one or more parameters of the carrier radio frequency. The process of changing one or more parameters of the carrier frequency according to changes in the parameters of the transmitted primary electrical signal (message) is called modulation. If modulation is performed by discrete signals, it is usually called manipulation. Thus, when transmitting messages on the transmitting side, a set of operations is performed: primary conversion, coding, modulation, amplification, and radiation. On the receiving side, reverse operations are performed: receiving radio waves, amplifying and filtering high-frequency oscillations, demodulating, decoding and converting a signal into a message. The source and the recipient of the message, the technical devices that provide the transmission of messages (signals), as well as the broadcasting environment make up the radio system.

A characteristic feature of the radio communication system is the distortion of signals due to interference. As a result, the recipient receives a message that is generally different from the sent message and is only an estimate [1].

Analysis of research. A quantitative measure of the quality of a radio communication system, as a complex system, is the criterion of efficiency.

The efficiency of the radio communication system is estimated by the degree of its technical perfection taking into account economic indicators. A complex system is described by a set of indicators (partial performance criteria). In practice, comparisons of systems are performed by one of the most 
important criteria, while others are constrained. The main of the partial criteria of efficiency (requirements) for radio communication systems are reliability, efficiency, noise immunity and reliability of communication.

Communication authenticity characterizes the ability of the communication system to reproduce the transmitted messages at the receiving points with a given accuracy. The criteria for assessing communication reliability are determined by the type of messages transmitted. The reliability of the transmission of voice messages is quantitatively evaluated by the rate of articulation (legibility), which is expressed as a percentage of correctly received elements of speech (phrases, words, sounds) of the total number of messages. The accuracy of digital message transmission can be judged by the probability of correctly receiving (or, conversely, the probability of error) of the code combinations of the source code. The promptness (timeliness) of communication determines the ability of the communication system to ensure the reception and delivery of messages or negotiation within the timeframe specified by management needs. Communication promptness can be estimated by the likelihood that the message will be fully delivered to the addressee within a specified time.Communication interference is the ability of the communication system to perform the tasks of transmitting messages in the conditions of influence of all kinds of obstacles. Criteria for the reliability of message transmission are often used to quantify noise immunity.

Under the reliability of communication means the property of the communication system to perform the tasks of transmitting messages, keeping for a specified period of time the values of the main characteristics (for example, the reliability of transmission) within the specified limits. The simplest estimates of hardware reliability are the probability of failure over the discussed time interval, the average time to failure [2].

Presentation of the main material and the justification of the results. According to the above classification, radio communication systems are interconnected systems operating in the wavelength range from decimeter to decimeter. Radio-relay, tropospheric, space-based systems, as well as command aviation radio, operate in this range. A feature of the band is that its waves have a slight diffraction around the Earth and the fundamental inhomogeneities of the Earth's surface and atmosphere. Therefore, the transmission of radio signals in this range is only possible within the line of sight.

The propagation of decimeter, centimeter, millimeter waves is significantly influenced by the lower atmosphere. Rain, clouds, and fog absorb and scatter radio waves shorter than $10 \mathrm{~cm}$. Centimeter and shorter waves are absorbed by air molecules and vapors of water at certain discrete frequencies. The general dependence of the conditions of propagation of electromagnetic waves on the wavelength in terrestrial conditions is characterized by the fact that the waves of $10 \mathrm{~cm}$ to $5 \mathrm{~m}$ are the least absorbed. To increase the line of sight, artificial Earth satellites are widely used.

Direct visibility radio systems provide close communication (within line of sight) of aircraft with ground control stations, communication between airplanes in the air, and communication between ground stations. They usually operate in meter and decimeter wavelengths. Thus, to provide communication over a given range, it is necessary to select the height of the receiving and transmitting antennas in a certain way, as well as to calculate the transmitter power and other system parameters so as to provide a given signal-tonoise ratio at the input of the receiver. If the aircraft is in communication with the ground station, then the maximum range is determined by the flight height of the aircraft and the lifting height of the ground antenna. In the case of communication between airplanes in the air, $\mathrm{h} 1$ and $\mathrm{h} 2$ are the altitudes of the participating aircraft.

The terrestrial radio range for antenna systems used in practice does not exceed $40 \ldots 50 \mathrm{~km}$. To increase the range, especially terrestrial communication, radio stations are usually placed on heights, artificial hills. The power of aircraft transmitters is selected provided the communication range is up to 500 ... $600 \mathrm{~km}$. Remote and military aviation aircraft, in addition to short-range radios, establish long-range radios that provide radio communication over the full range of the aircraft.

In aeronautical communication systems, direct line-of-sight uses, as a rule, antennas raised above the Earth. In terrestrial radios, antennas are placed on masts at a height of ten meters or more in order to achieve the required communication distance, and the antennas of airborne ultra short wave radios are in principle a group of raised antennas. Practically, the antenna lift height is several times the working wavelength. In this case, the intensity of the electric field at the location of the receiving antenna can be found by the method of geometric optics as a result of the interference of the direct beam and the beam reflected from the earth's surface. It should be noted that the following features of the line-of-sight radio systems, due mainly to the use of the meter and decimeter ranges of radio waves. They provide high communication stability, since the nature of the propagation of radio waves is slightly dependent on the time of day and year, meteorological 
conditions, especially when operating at frequencies not higher than $3 \mathrm{GHz}$. The absorption in the atmosphere, as practice shows, is relatively small. Substantial uptake and molecular uptake are observed only in centimeter and shorter wavelengths. The main types of radio interference in the meter and decimeter ranges are space noises and internal noise of the equipment, as well as interference created by other radio stations. The relatively weak propensity for interference is also explained by the fact that only such interference is affected by such a system, the sources of which are within the direct line of sight of the receiving device of the system. For the same reason, there are also certain difficulties in creating deliberate obstacles to such systems. The noise immunity can also be improved by the fact that the systems considered may use directional antennas, especially in terrestrial communication systems. In line-of-sight communication systems, the multiplicative obstacle is weakly detected, since the communication is mainly a direct beam, although when communicating between planes, this type of interference affects the quality of the communication, since in addition to the direct beam, the effect on the receiver is reflected. signal from the earth's surface.

An important feature of these communication systems is that they provide reliable transmission of information at high speeds (up to several thousand bps), which is very important for high-speed digital communication. It is also possible to use broadband signals in these systems, multichannel methods of transmitting information, as well as rearranging the transceiver equipment over a wide frequency range.

The relatively small size and mass of ultra-short wave equipment, the ability to use antennas with small aerodynamic drag and small size have made these systems widely used for airborne communication. Airborne radio equipment of any aircraft and helicopter typically includes a meter or decimeter radio station that provides close communication between the aircraft and the ground and between aircraft. The main drawback of direct line radio systems is the limited range. Therefore, on long lines there is a need to relay signals. A classic example of a relay communication system is the relay communication system used in aviation to arrange terrestrial radio communication on decimeter or shorter waves.

Signal relaying is also widely used in aerial radio networks to increase communication distance beyond line of sight, to ensure low-flying aircraft communicate with each other and with ground control points. In this case, the relay is usually installed on board the aircraft flying in the area. The relay apparatus provides reception, conversion, amplification and subsequent transmission of radio signals at simplex and duplex two-way radio communication between the radio terminal end points. The control of the repeater's on-board equipment is made remotely from ground points or by the operator on board the aircraft.

The phenomenon of circumnavigation occurs due to the fact that short waves, when they have a weak absorption, can one or more times bend the globe, repeatedly reflecting from the ionosphere and the earth's surface. The radio moon is interfering with communication lines for more than $10,000 \mathrm{~km}$. (Pic. 1).

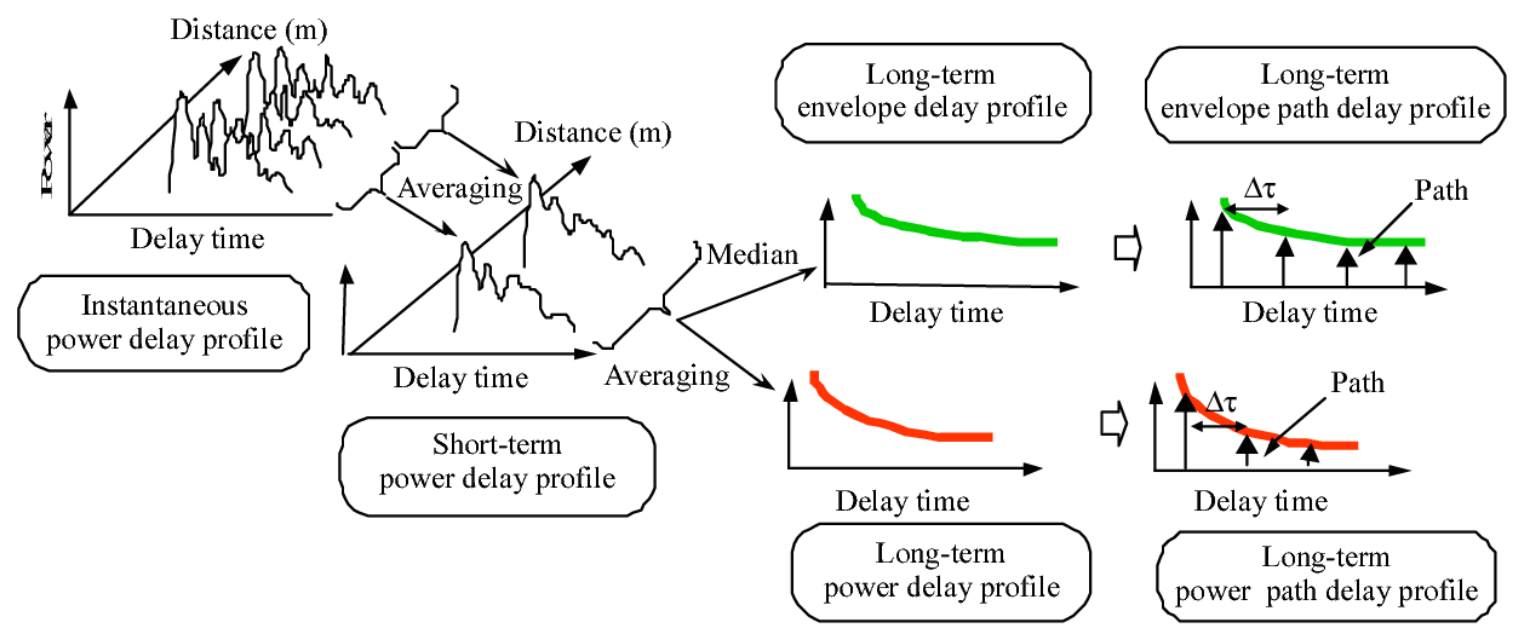

Pic 1. Features of radio waves propagation

Currently widely used to organize long-range communication on meter and shorter waves, the work of which is based on the effect of long-range propagation of radio waves due to tropospheric and ionospheric scattering or reflection from ionized traces of meteors.

Thus, for continuous communication, you must change the operating wavelengths in flight according to a previously scheduled schedule. 
In addition, when providing uninterrupted radio communications on short waves, account should be taken of such interfering phenomena as signal fading, circumnavigation, and the presence of dead zones.

The fading of the signals, as already noted, is explained by the interference (overlay) of two or many spatial waves coming to the point of reception from one transmitter, but in different ways, because they are reflected from different regions of layer $\mathrm{F}$. When the waves are added in phase, there is a gain signal, against phase - damping. For anti-fading, simultaneous reception of several spaced antennas, transmission and reception of signals simultaneously on two or more operating waves, waves of different polarization.

A characteristic feature of short-wave systems is that they are largely exposed to the harmful effect of a multiplicative interference that occurs in the course of propagation of radio waves in the ionosphere and manifests itself in the form of fluctuations in the amplitude and phase of the received signal. Fast and slow fading are observed.

Rapid fading occurs mainly due to the interference of many rays coming into the receiving point, the phase of which due to the variability of the ionized layers continuously and randomly changes. The amplitude of the signal thus varies by tens and even hundreds of times. The fading period ranges from ten fractions of seconds to a few seconds.

Slow fading of a signal with a period of several minutes or more is associated with a change in the absorption of radio waves in the propagation medium, a change in the heterogeneity of the ionosphere, as well as due to the interference of ordinary and unusual components of the signal. Slow changes in signal levels can exceed the corresponding fluctuations in fast fading. Hourly, daily, seasonal periods of changes in the signal level often depend on changes in the illumination of the ionosphere and absorption in the propagation medium.

With fast fading at the receiving point, the received signal can be represented as the sum of the regular signal component and the multiple scattered components with random amplitudes and phases.

The presence in the communication channels of fading, which is called the multiplicative obstacle, significantly reduces the likelihood of transmitting information in connection with such circumstances [3-4].

An effective means of enhancing the immunity of short-wave channels with fading is diversity reception. The principle of diversity receiving is that the transmitted message on the receiving side is played not by one, but by two or more signals carrying the same information. These signals may be signals from different transmitters operating at different frequencies, or signals from a single transmitter received at different antennas, spaced in space or in polarization. It is possible to spread reception by time or by the angle of incoming rays. It is necessary to select a degree of diversity at which the fading of the diversity signals will be almost mutually independent, and therefore the probability of their simultaneous attenuation will be much less likely to attenuate a single signal. The principle of implementation of the auto selection is as follows. The comparison device produces an estimate of the oscillation received on each branch and a comparison of the received estimates. As a result, a control signal is generated that connects the branch with the largest signal to the main receiving channel. In spatial spacing, the branch selection device may switch, for example, the outputs of the spaced antennas (if a common receiver is used) or the outputs of the receivers (if each branch uses its own receiver). Obviously, the noise immunity of the reception depends on the method of signal processing in the main receiving channel [5].

To ensure autonomous operation, the control system must include such terminal devices as a microphone, telephone, telegraph key. When using a radio station in a communication node, it is possible to connect to the radio the terminal devices located in the hardware nodes, as well as the radio control system, which allows to organize an individual remote control line. Pulse signal transmitters, as a rule, must operate in the frequency range, allow for rapid tuning from one wave to another, provide the required power of the vibrations emitted and high frequency stability.

The power of the transmitter and the method of controlling its oscillations are determined in the process of sketchy design of the relay line, based on the requirements for noise immunity on the line and the allowable magnitude of attenuation overlapping the station (Pic 2).

Pulse signal receivers play a major role in providing high noise immunity. They determine the level of the minimum signal at which communication is possible on the relay line, largely the amount of noise voltage at the outputs of the communication channels.

The main feature of pulse signal receivers is their construction, which ensures the minimum probability of erroneous pulse reception and in some cases accurate reproduction of their shape.

The interference voltage acting on the receivers leads to the parasitic modulation of the pulse signals coming to their inputs and to the erroneous reception of these signals, ie to the registration of pulses at times when there is no signal at the input (the occurrence of an error pulse), and to the registration pauses when 
there is a pulse at the input of the receiver (suppression of signal impulses). As a rule, both of these phenomena are always observed in any pulse receiver. However, at low interference (or high level of useful signals), the probability of mistakenly receiving impulses is small and the main effect of interference is manifested in the distortion of the signal, whereas at high levels of interference (or small value of useful signals) the interfering action of such received impulses is so large, caused by distortion of the pulse shape may not be taken into account. From this it follows that the main task of the receiver is to provide a low probability of mistakenly receiving pulse signals. The probability of erroneous reception of impulse signals depends on the type of signal manipulation and the method of receiving it [6].

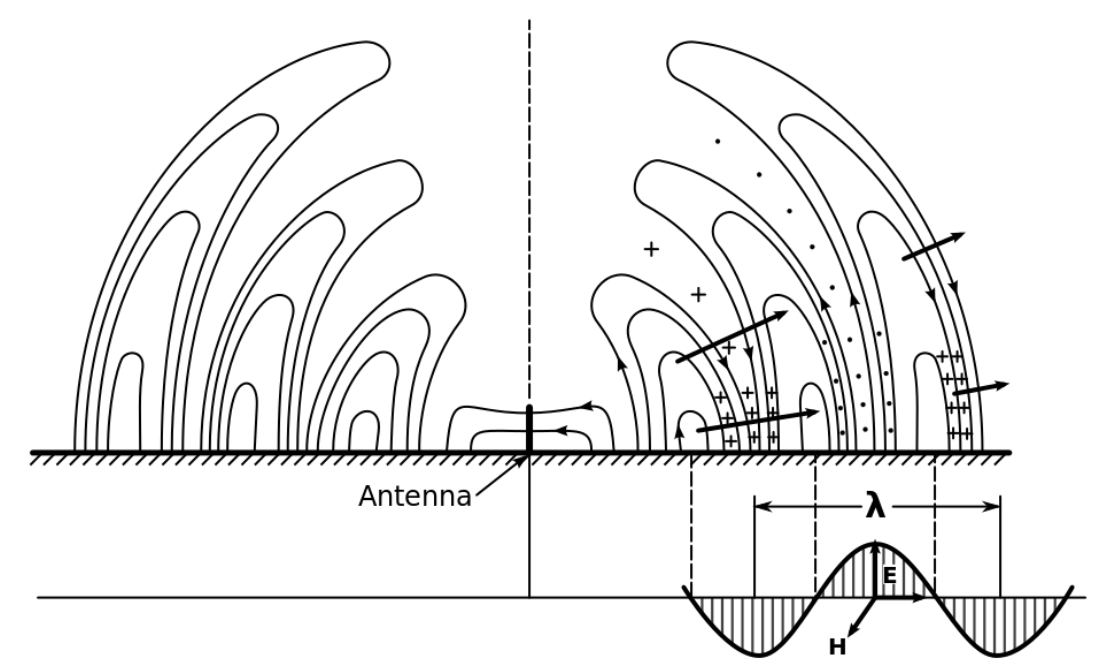

Pic 2. Frequency modulation of radio waves

The cause of interference is linear distortions, such as frequency and phase distortions in the high frequency and video parts of the above devices. These distortions are manifested in the change in the shape and duration of the amplifying impulses. For example, limitation or blockage of the frequency response of the upper frequencies leads to an increase in the time of decay and increase of the pulses;

If there is any residual voltage from the previous signal pulses by the moment of the next pulse, this will change the shape and shift the signal that surrounds the pulses. As a result, parasitic pulse modulation in amplitude, phase and duration is detected [7].

Quantization noises are due to errors in the approximation of the analog signal during its quantization by level and sampling over time. Their size depends on the quantization step, the number of levels, the method of breaking the level scale, the statistics of the input signal. In this case, the incoming messages are quantized both in time and in amplitude. Therefore, the signal transmitted on the line represents impulses of the same shape, which follow at strictly defined points of the time axis.

However, in the case of delta modulation, the discrete values of the message function are not encoded and are not transmitted at all to the communication channel. The signal on the line characterizes only the changes that occur with the message function - its increase or decrease. These changes are transmitted by impulses of the same shape and duration.

Noises in the communication channel affect the transmission of information if the noise voltage suppresses the pulses of the signal or the noise generates incorrect pulses at the clock points of the time axis. Noises in the channel of the pulse are distorted when the pulse shape is distorted, since all pulses have the same parameters and can be completely restored in amplitude, shape and duration when correctly found.

The signal-to-noise ratio at the output of the channel depends on the modulation parameters, but is determined mainly by the probability of erroneous pulse reception.

As noted above, one of the basic conditions for the proper operation of the timing lines is the correct pulse distribution of the received group sequence on the corresponding channel node. The line in which such compliance is ensured is called synchronous, and the set of synchronizing devices (and measures) is called the synchronization system.

In practice, in-line synchronization means that each receiver node only opens for the duration of its channel section of time and closes during the entire other time interval [8-9].

These tasks are solved with the help of special devices called, respectively, clocking devices and channel search devices. This distribution is relatively relative, as there is often interaction between these 
devices. Slow phase output refers to the offset of the switching pulses relative to the received pulses with a frequency that is a few percent $\mathrm{Hz}$ and even less. These displacements are related either to temperature changes in the apparatus or to slow fading of group propagation times at line intervals (especially tropospheric ones). Slow phase shifts can lead to such temporal divergence of switching pulses with pulses that are accepted that the pulses of the previous or next channels may occur, and the failure of their own pulses may also occur.

Such parasitic modulation occurs due to the interference of the receiver and signals transmitted over the line channels. Parasitic modulation manifests itself in the form of interference on the communication channel. These interferences are called synchronization interferences. The accuracy requirements with slow and fast phase shifts depend on the type of modulation and coding accepted in the line, the number of channels and their interference protection, and more.

Under such a rule of operation is understood that the synchronization system is able to solve two main problems. The first of these is to create in the receiver by controlling the voltages (impulses) issued by the system distributor. The second task is to accurately match the switching pulses of a given channel node with the pulse arrival time of this channel in a group signal, ie, the task is to search for a synchronous state (search for synchronism) and hold it after finding [10].

Conclusion and prospects for further research

Thus, the issues of improving the efficiency of radio communication systems (aviation, including) can be solved by using both special types of signals and different methods of their processing. Broad possibilities for improving the efficiency of radio communications are opened by the use of digital signals, which processing by means of specialized computers or devices based on programmable microprocessors, allows to create onboard and terrestrial complexes that automatically adapt to the changing conditions of the information space and types of signals used.

Channel synchronization, that is, the distribution of pulses in a group sequence by its channel nodes, is possible if the signal of one of the channels has its characteristic that distinguishes it from the other channels. In synchronous systems, it is quite common for such distinction features to be assigned to only one channel, which is called a marker or synchronization channel. Other channels are determined by the marker count. The hallmarks of the distinction may be: additional modulation of the clock pulses by a sine wave signal; other duration of clock pulses; form of clock pulses. Among the clock signals may be pulse groups that use special codes. The choice of a feature depends on the structure of the group signal, the requirements for the speed of response of the system to the output from the synchronism, the conditions of matching the receiver with the form of the clock signal and the like. The selection criterion is, as a rule, a low likelihood of such a feature being formed in signals from other channels or in a group signal during modulation and interference.

The synchronization system is built to respond to the presence or absence of difference markers. The absence in the control device (channel search system) of a signal with known features is transformed in the synchronization system to search for this signal. The search ends when the clock is found.

\section{References}

1. Aviation radio communication devices. V.I. Tikhonov. - M.: VIA, 2006. - 442s.

2. Velichkin A.I., Azarov O.S., Sayutin O.V. Air Force Communication and Communication System. A.I. Velichkin. - M .: VIA, 1985. - 324s.

3. Varakin L.E. Communication systems with noise-like signals. - M.: Radio and communication, 2005. - 384s.

4. Telecommunication. Introduction to the specialty. Textbook for high schools. / V.G. Durnev. - M .: Radio and communication, 1988. - 240s.

5. Pavlova G.G. Satellite communication and broadcasting systems [Textbook. manual] [Text] / G.G. Pavlova // DVPI them. VV Kuibyshev: - Vladivostok, 2009. - 175 p.

6. Ponomarev, L.I. Modeling of mobile communication systems [Text] / L.I. Ponomarev, T.L. Mankevich, // The successes of modern radio electronics, - 1999. - No 8. - P.45-58.

7. Petrov B.M. Electrodynamics and Propagation of Radio Waves [Text] / B.M. Petrov - Moscow: Hot Line-Telecom, 2011.

8. Quasioptic methods in modeling problems of propagation of radio waves along the Earth's surface [Text] / Sukhorukov, A.P., Dudov, R.A., Korolev, A.F. etc .; [under ed. Turchaninova A.V.] // Nonlinear world. - 2005. - No.1-2. - Vol. 3 - P.107-115.

9. Radiocommunication systems: Textbook for universities / N.I. Kalashnikov, E.I. Krupitsky, I.L. Dorodnov, V.I. Nosov, N.I. Kalashnikov. - M .: Radio and communication, 2008. - 352s.

10. Feinberg, E.L. Propagation of radio waves along the earth's surface [Text] / E.L. Feinberg - Moscow: USSR Academy of Sciences, 1999. - 546c. 